\title{
Educação Física, formação inicial de professores e o mercado de trabalho
}

Physical education, initial teacher training and the labour market

Andreia Cristina Metzner*

Centro Universitário UNIFAFIBE

Resumo O presente estudo teve como objetivos verificar a opinião de estudantes do curso de licenciatura em Educação Física em relação aos conhecimentos adquiridos durante a formação inicial e o seu desempenho profissional, bem como, as suas expectativas em relação ao mercado de trabalho. Participaram desse estudo 31 alunos do último ano do curso de Licenciatura em Educação Física. Os resultados indicam que os conhecimentos relacionados a didática e as diferentes metodologias de ensino são os mais importantes para a formação inicial do futuro professor de Educação Física e que as principais expectativas em relação ao mercado de trabalho envolvem a aprovação em concurso público e atuação na educação básica.

PALAVRAS-CHAVE: Licenciatura; Ensino superior; Expectativas.

Abstract The present study aimed to verify the opinion of students of degree in Physical Education in relation to the knowledge acquired during initial training and professional performance as well as their expectations for the job market. Study participants were 31 students in the final year of the Bachelor's Degree in Physical Education. The results indicate that the knowledge related to teaching and different teaching methodologies are most important for the initial formation of future physical education teacher and the main expectations of the labor market involve the approval of tender and performance in basic education.

KEYWORDS: Licenciate degree; Higher education; Expectations. 


\section{Introdução}

As questões que envolvem a formação de professores tanto no âmbito da formação inicial quanto da formação continuada, nas últimas décadas, têm despertado interesse dos pesquisadores visando compreender quais são as limitações na formação e atuação docente.

A formação inicial pode ser definida como o período de aquisição dos conhecimentos/capacidades essenciais para iniciar o exercício de uma profissão. Ou seja, é o período de preparação e desenvolvimento do futuro profissional.

Em relação aos cursos de licenciatura, a formação inicial tem como foco principal a formação de profissionais qualificados para o exercício do trabalho pedagógico nas diversas esferas educacionais.

Para atender as necessidades da realidade escolar, as estruturas curriculares precisam ser modificadas e adequadas a partir do tempo histórico e social em que vivemos, bem como, das exigências do mercado de trabalho.

No caso da Educação Física, ainda hoje, as suas raízes históricas, influenciadas pelas instituições militares, propiciam a valorização da prática em detrimento da teoria em grande parte dos cursos de formação docente. Porém, aos poucos, essa situação está se transformando, pois os alunos/gestores/comunidade escolar pertencentes as diferentes instituições e níveis de ensino estão cobrando do professor de Educação Física uma prática pedagógica que vai além dos conteúdos exclusivamente práticos.

Assim, para que seja possível desenvolver um ensino crítico e transformador, o futuro professor de Educação Física precisa ter acesso a uma gama de conhecimentos, durante a formação inicial, que permitam a emancipação do educando e compreensão da realidade concreta.

Com base no que foi exposto surgem as seguintes questões: quais conhecimentos adquiridos durante a formação inicial em Educação Física são necessários, na opinião dos alunos, para que o licenciado possa ter um bom desempenho profissional? E quais as expectativas dos formandos em relação ao mercado de trabalho?

$\mathrm{Na}$ busca de desvelar tais indagações, esse estudo teve como objetivos verificar a opinião de estudantes do curso de licenciatura em Educação Física em relação aos conhecimentos adquiridos durante a formação inicial e o seu desempenho profissional, bem como, as suas expectativas em relação ao mercado de trabalho.

Esse trabalho tem como referencial a pesquisa qualitativa. Participaram desse estudo 31 alunos do último ano do curso de Licenciatura em Educação Física pertencentes a uma instituição particular de Ensino Superior, localizada no interior do Estado de São Paulo.

O instrumento metodológico utilizado foi um questionário composto por duas questões abertas: Quais conhecimentos adquiridos durante a formação inicial são necessários para que o licenciado possa ter um bom desempenho profissional?; Quais são as suas expectativas em relação ao mercado de trabalho? 
Após a aplicação dos questionários, os dados foram organizados em grupos de categorias com a finalidade de desenvolver a análise e discussão dos mesmos. Essas categorias foram estruturadas da seguinte forma: a-) Formação Inicial do Professor de Educação Física; b-) Mercado de Trabalho.

\title{
Formação inicial do professor de Educação Física
}

O artigo 62 da Lei de Diretrizes e Bases da Educação Nacional de 20 de Dezembro de 1996 (Lei no 9.394) aponta que "a formação de docentes para atuar na educação básica far-se-á em nível superior, em curso de licenciatura, de graduação plena, em universidades e institutos superiores de educação". (BRASIL, 1996, p.56).

A partir desta Lei outras reformas surgiram visando ampliar a reestruturação dos cursos de formação docente. Dentre esses documentos podemos citar a Resolução do Conselho Nacional de Educação CNE/CP 1, de 18 de fevereiro de 2002, que institui as Diretrizes Curriculares Nacionais para a formação de professores da Educação Básica.

$\mathrm{O}$ artigo $2^{\circ}$ das Diretrizes Curriculares indica que a organização curricular das licenciaturas deverá preparar o futuro professor para: desenvolver o ensino visando à aprendizagem do aluno; saber lidar com a diversidade; promover atividades de enriquecimento cultural; aprimorar as práticas investigativas; elaborar e executar projetos de desenvolvimento dos conteúdos curriculares; utilizar metodologias, estratégias e materiais de apoio inovadores; desenvolver hábitos de colaboração e trabalho em equipe. (BRASIL, 2002).

Em relação aos cursos de licenciatura em Educação Física, os mesmos visam formar professores para atuar na Educação Básica (instituições públicas e privadas de ensino infantil, fundamental, médio e superior; instituições, entidades ou órgãos que atuam com populações especiais, bem como, secretarias municipais, estaduais e nacionais voltadas à área da Educação Física), no sentido de:

\begin{abstract}
desenvolver ações teórico-práticas em que os conhecimentos e saberes acadêmicos contribuam na formação do ser humano em sua totalidade; possibilitar uma formação político-social, dentro de uma abordagem histórico-crítica, em diferentes manifestações da cultura corporal, compromissada com a educação emancipatória; possibilitar uma formação técnico-profissional visando o aperfeiçoamento de habilidades, capacidades e competências necessárias ao exercício profissional/docente. (KRÜGER, 2007, p.21-22).
\end{abstract}

No âmbito escolar, a prática pedagógica do professor de Educação Física pautar-se-á na Cultura Corporal de Movimento. De acordo com Soares et. al (1992), Cultura Corporal pode ser definida como:

acervo de formas de representação do mundo que o homem tem produzido no decorrer da história, exteriorizadas pela expressão corporal: jogos, danças, lutas, exercícios ginásticos, esporte, malabarismo, contorcionismo, mímica e outros, que podem ser identificados como formas de representação simbólica de realidades vividas pelo homem, historicamente criadas e culturalmente desenvolvidas. (SOARES, et al., 1992, p. 38). 
Notamos que a preparação para o exercício profissional específico do professor de Educação Física vai além dos conteúdos práticos. Assim, o primeiro passo para formar professores qualificados e capacitados para desenvolver um bom trabalho pedagógico em diferentes campos de atuação é compreender que não pode haver ruptura entre a teoria e a prática nos cursos de Educação Física, pois esses dois aspectos do trabalho do professor são necessários para dar unidade a prática pedagógica.

Segundo Vasquez (1997) a teoria e a prática são componentes indissolúveis da práxis. O autor complementa dizendo que práxis é, na verdade, "atividade teórica -prática, ou seja, tem um lado ideal, teórico, e um lado material, propriamente prático com a particularidade de que só artificialmente, por um processo de abstração, podemos separar, isolar um do outro" (p.241).

A partir do momento que a teoria e a prática caminham juntas é possível viandar para uma nova realidade da Educação Física escolar, desvinculada do esportivismo e da prática pela prática.

Em relação aos conhecimentos práticos e teóricos inseridos nas diversas disciplinas curriculares e adquiridos na formação inicial dos professores de Educação Física, os dados coletados e apresentados no Gráfico 1 apontam que a maioria dos alunos acredita que os conhecimentos relacionados a didática e as diferentes metodologias de ensino são os mais importantes para a formação inicial do futuro professor de Educação Física. Em seguida, os conteúdos que abordam as fases de desenvolvimento humano, questões éticas e as noções de primeiros socorros, são considerados necessários para ter um bom desempenho profissional. As disciplinas que tratam de questões práticas e que envolvem a Educação Física inclusiva também foram citadas.

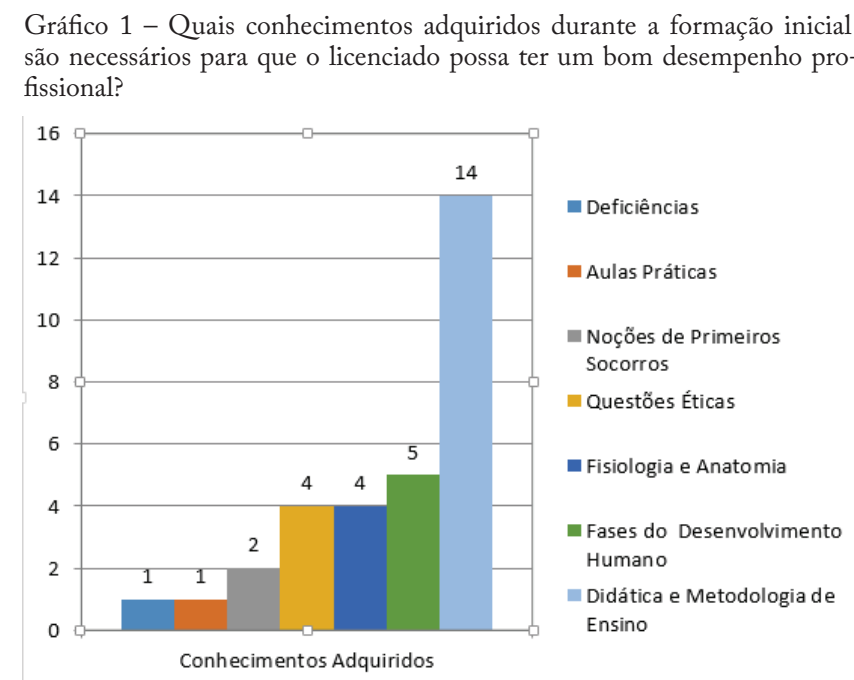

As disciplinas eminentemente pedagógicas, como a Didática e as Metodologias de Ensino, operam a interligação entre a teoria e a prática e são fundamentais para embasar e direcionar a prática pedagógica dos professores. Por isso, a maioria dos alunos apontou que esses conhecimentos são importantes para formação do licenciado. 
Segundo Libâneo (2006), essas disciplinas abordam o processo de ensino e aprendizagem como um todo, ou seja, envolvem as questões dos princípios, finalidades, objetivos, conteúdos, métodos, recursos, avaliação e organização da prática pedagógica do professor.

Esses elementos oferecem o suporte necessário para o bom desempenho do professor nas instituições de ensino tanto nas questões práticas quanto nas questões burocráticas. Ou seja, o dia a dia do professor na escola envolve a prática pedagógica propriamente dita e também as exigências administrativas como, por exemplo, preenchimento do Diário de Classe, elaboração do Plano de Ensino, entrega de relatórios referentes às atividades e projetos realizados na disciplina, etc.

Destarte, na visão dos alunos participantes da pesquisa, os conteúdos presentes nas disciplinas de cunho pedagógico oferecem uma gama de conhecimentos sobre o ensino que serve para garantir a sua eficiência e isso reflete diretamente no desempenho profissional.

No currículo dos cursos de Licenciatura em Educação Física, além das disciplinas de cunho pedagógico, encontramos disciplinas que buscam compreender e analisar o movimento humano sob o ponto de vista anatômico e fisiológico, bem como, disciplinas que estudam as diferentes fases do desenvolvimento motor e os processos de ensino-aprendizagem de habilidades motoras. Os conhecimentos adquiridos nessas disciplinas também foram citados pelos participantes da pesquisa como necessários para a atuação do licenciado.

O objeto de estudo da Educação Física é o movimento humano, portanto, ao apontar esses conhecimentos como imprescindíveis para a formação do professor de Educação Física, os participantes estão de acordo com o que é abordado no artigo $3^{\circ}$ das Diretrizes Curriculares Nacionais para os cursos de graduação em Educação Física: "a Educação Física é uma área de conhecimento e de intervenção acadêmico-profissional que tem como objeto de estudo e de aplicação o movimento humano" (BRASIL, 2004).

Essas Diretrizes complementam essa informação dizendo, no Art. $8^{\circ}$, que:

Para o Curso de Formação de Professores da Educação Básica, licenciatura plena em Educação Física, as unidades de conhecimento específico que constituem o objeto de ensino do componente curricular Educação Física serão aquelas que tratam das dimensões biológicas, sociais, culturais, didático-pedagógicas, técnico-instrumentais do movimento humano. (BRASIL, 2004).

Segundo Fonseca (1988), o movimento, como meio de exploração motora, permite a apropriação das qualidades dos objetos do real de onde surge a significação, a conservação e a organização da informação cerebral. Deste modo, podemos dizer que o movimento humano é a base do pensamento.

O autor complementa que "a informação intersensorial do ser humano é tanto mais significativa quanto mais cinestésica, isto é, quanto maior relação tiver com a experiência prática e motora" (FONSECA, 1988, p.307). 
Outro ponto de destaque nas respostas dos participantes da pesquisa foi em relação às questões éticas abordadas no curso: cinco alunos apontaram como sendo imprescindível para a formação inicial do licenciado em Educação Física. Esse é um dado interessante, pois segundo Menezes et. al (2011),em muitos cursos de formação de professores é privilegiado:

muito mais os aspectos relativos ao domínio dos conteúdos disciplinares, negligenciando a formação humanista necessária ao enfrentamento dos desafios postos pelas mudanças aceleradas e pelos diferentes conflitos existentes nas sociedades contemporâneas (MENEZES, et al., 2011, p.69).

Segundo Impolcetto e Darido (2007, p.15), a ética pode ser compreendida "como aquilo que vetoriza determinada ação, ao lhe ofertar uma origem e destino específico". Além disso, as autoras assinalam que a ética está ligada às noções de bem e mal, certo e errado, justo e injusto, a partir do "conjunto de valores que os homens admitem por tradição, por hábito ou pela adesão a um conjunto de crenças”. No caso da instituição de ensino pesquisada, os dados levam a crer que durante a formação inicial dos licenciados ocorrem discussões relacionadas a ética e por isso foram apontados pelos participantes do estudo como um conhecimento necessário para o bom desempenho profissional.

Não existe uma receita para o futuro professor que possa prever como deve ser a sua atuação em todos os seus momentos do cotidiano escolar ou diante dos problemas que enfrentará em sua carreira profissional. No entanto, as instituições de formação profissional devem buscar estratégias que favoreçam a criação de condições para a transformação do ensino e a formação de professores que atendam as necessidades da sociedade em permanente mudança.

É consenso entre vários autores, segundo Cesário (2008), que:

o papel das instituições formadoras nas sociedades contemporâneas é de indicar com clareza para o futuro professor que conhecimentos são necessários para poder aprender a ensinar em diferentes contextos sociais e qual a relação entre o que ele aprende na licenciatura e o currículo que trabalhará nas escolas (CESÁRIO, 2008, p. 20).

Para Kuenzer (1999, p.172) "ao professor não basta conhecer o conteúdo específico de sua área; ele deverá ser capaz de transpô-lo para situações educativas”.

A escola é um ambiente singular, incerto, imprevisível e complexo, por isso, os futuros professores devem estar preparados para ensinar em diferentes contextos e, ao mesmo tempo, proporcionar uma aprendizagem significativa aos seus alunos (CESÁRIO, 2008).

\section{Mercado de trabalho}

A formação do professor de Educação Física, segundo Cruz (2011, p.34), "está embasada na docência como identidade profissional, ou seja, em ser professor". Portanto, a formação do profissional de Educação Física que irá atuar no âmbito es- 
colar acontece primordialmente por meio das licenciaturas, em instituições de Ensino Superior.

A Educação Física, como um componente curricular obrigatório da Educação Básica, permite que os licenciados dessa área atuem em diferentes níveis de ensino: Educação Infantil, Ensino Fundamental e Ensino Médio. (BRASIL, 1996).

Corroborando com essa afirmação, Cruz (2011, p.36-37) aponta que como "a licenciatura não consegue atender as exigências de todos os espaços nos quais atuam o profissional de Educação Física, estando, portanto, o bacharelado apto a preparar o profissional para o "outro mercado de trabalho".

Esse outro mercado de trabalho que o autor se refere inclui os espaços não formais de atuação profissional do bacharel em Educação Física, tais como: clubes, academias, hotéis, cruzeiros, clínicas de reabilitação, centros de treinamentos, promoção e organização de eventos esportivos/recreativos, etc. Portanto, o campo de trabalho do licenciado configura-se pelos espaços formais de ensino.

O trabalho é um processo que liga o homem à natureza e ao mesmo tempo em que o homem opera mudanças na natureza também se modifica. Ou seja, é por meio do trabalho humano que ocorre o processo de transformação da realidade pelo homem no qual o homem transforma a si próprio. (MARTINS, 2011).

Antes de tudo, o trabalho é um processo entre o homem e a Natureza, um processo em que o homem, por sua própria ação, media, regula e controla seu metabolismo com a Natureza. Ele mesmo se defronta com a matéria natural como uma força natural. Ele põe em movimento as forças naturais pertencentes à sua corporalidade, braços e pernas, cabeça e mão, a fim de apropriar-se da matéria natural numa forma para sua própria vida. Ao atuar, por meio desse movimento sobre a Natureza externa a ele e ao modificá-la, ele modifica ao mesmo tempo sua própria natureza. (MARX,1989, p.149).

Para Marx (1989), o trabalho é uma condição da existência humana, independentemente de qual seja a forma de sociedade.

Em relação ao trabalho do professor, o mesmo possui certas particularidades, por isso não pode ser comparado, por exemplo, ao trabalho realizado em uma fábrica de automóveis. Uma das especificidades do trabalho do professor é que o mesmo não gera mais valia, que é a base do sistema capitalista e está presente no trabalho produtivo.

Basso (1998), não nega o vínculo das formas capitalistas de produção com as transformações ocorridas nas condições de trabalho dos professores. Porém, a autora ressalta que a atividade de ensino não tem como finalidade direta a criação de valor.

Nessa situação, o trabalho docente propicia uma certa autonomia ao professor em relação a escolha de metodologias, seleção de conteúdos e de atividades mais adequadas aos alunos, segundo o interesse ou suas necessidades e dificuldades. Dessa forma, as mudanças ocorridas no âmbito escolar dependem, em grande parte, de uma formação adequada do professor e do entendimento claro do significado e do sentido de seu trabalho. (BASSO, 1998). 
No caso dos professores,

o significado de seu trabalho é formado pela finalidade da ação de ensinar, isto é, pelo seu objetivo e pelo conteúdo concreto efetivado através das operações realizadas conscientemente pelo professor, considerando as condições reais e objetivas na condução do processo de apropriação do conhecimento pelo aluno. (BASSO, 1998, p. 24).

$\mathrm{Na}$ escola, a apropriação do conhecimento realiza-se de forma institucionalizada e sistematizada, sendo o professor o responsável pela mediação necessária entre o aluno e o conhecimento. (BASSO, 1998).

Assim, na educação formal, a atividade do professor engloba "um conjunto de ações intencionais, conscientes, dirigidas para um fim específico" (BASSO, 1998, p. 25).

Além disso, o dia a dia do professor é marcado por um constante processo de reflexão sobre a sua prática pedagógica, os problemas encontrados na rotina escolar, as relações estabelecidas com os seus colegas de trabalho e com a organização políticopedagógica das instituições de ensino.

Portanto, para se alcançar o êxito profissional, o professor precisa ser capaz de "manejar situações concretas do cotidiano e resolver problemas práticos mediante a integração "inteligente e criativa" do conhecimento e da técnica" (MARTINS, 2011, p.13).

Isso significa que o professor deve elaborar ações adequadas em relação aos contextos e as próprias possibilidades existentes nas instituições de ensino onde atua.

Em relação ao perfil atual do professor de Educação Física, hoje, é exigido que ele seja muito mais do que um mero "animador" ou "recreacionista" que cativa a atenção e simpatia dos alunos. Ele precisará, segundo Kuenzer (1999, p.172), "ser um profundo conhecedor da sociedade de seu tempo, das relações entre educação, economia e sociedade, dos conteúdos específicos, das formas de ensinar, e daquele que é a razão do seu trabalho: o aluno".

\begin{abstract}
Ao invés da mera transmissão de informações em pacotes fechados e impessoais, os programas de formação inicial em Educação Física necessitam desestabilizar a estrutura organizacional da base de conhecimentos dos estudantes-professores, instigando-os ao questionamento e à dúvida por meio de práticas pedagógicas que gerem inquietação e desejo pela descoberta, apurando seu poder de argumentação e seu senso crítico (MARCON, GRAÇA, NASCIMENTO, 2011, p. 506).
\end{abstract}

Por isso, o que se espera dos cursos de formação inicial em Educação Física é que destinem espaços suficientes para que os alunos/futuros professores possam construir uma base sólida de conhecimentos teóricos e práticos subsidiando o trabalho docente e capacitando-os para transitar pelos diferentes níveis de ensino.

Vimos que o campo de atuação profissional do licenciado em Educação Física engloba os espaços formais de ensino. Porém, dentro do âmbito escolar, os futuros professores possuem expectativas sobre esse mercado de trabalho, são elas: 
Gráfico 2 - Quais são as suas expectativas em relação ao mercado de trabalho?

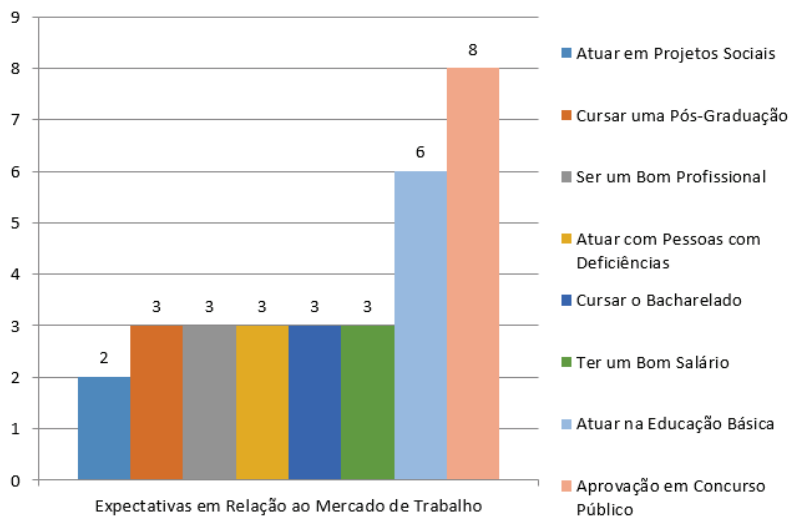

Notamos no gráfico 2 que as expectativas em relação ao mercado de trabalho envolvem a aprovação em concurso público e atuação na Educação Básica, como os principais objetivos dos alunos.

A estabilidade financeira ainda é um dos principais objetivos dos licenciados sendo acompanhada pelo interesse em trabalhar na Educação Básica: Educação Infantil, Ensino Fundamental e Ensino Médio. O aumento no número de vagas para professores em concursos públicos é um grande atrativo para a escolha da carreira profissional e isso pode ser confirmado a partir das respostas apresentadas pelos participantes da pesquisa.

A decisão de ser professor, segundo Giesta (2001, p.7), "pode representar a concretização de um ideal, a efetivação de um desejo de contribuir na formação "do outro e de si mesmo", a possibilidade de mobilidade social ou de emprego com certa estabilidade".

Os futuros professores têm como foco a aprovação em concursos públicos e essa expectativa é movida pela idéia de que o emprego público traz estabilidade e segurança financeira. Porém, acreditamos que o fato do candidato admitido por concurso ter a estabilidade nesse emprego garantida por lei não pode ser a única e exclusiva motivação para a escolha da profissão. É preciso ponderar a todos os aspectos que envolvem o trabalho docente para evitar frustrações futuras, bem como, a má qualidade das aulas desenvolvidas nas instituições de ensino.

São apresentadas também como expectativas dos futuros licenciados: ter um bom salário, cursar o Bacharelado, atuar com pessoas com deficiências, ser um bom profissional, cursar uma Pós-Graduação e atuar em Projetos Sociais.

Tais resultados contrariam, de certo modo, a concepção de que os alunos que procuram um curso de licenciatura têm o intuito de atuar como professores no âmbito escolar. Talvez, a busca por outro ambiente de trabalho esteja atrelado a perda de prestígio do professor decorrente dos baixos salários, violência nas escolas e ausência de políticas públicas claras, eficientes e coerentes com a realidade atual do ensino. 
A desvalorização dos saberes docentes e da figura do professor pelos governantes, escolares e sociedade de uma forma em geral, fazem com que a habilitação em licenciatura tenha certo desprestígio comparado ao bacharelado, por isso, alguns alunos decidem cursar o bacharelado após concluírem o curso de licenciatura. Nas instituições de ensino superior que possuem cursos voltados para essas duas formações (como é o caso da instituição pesquisada nesse estudo) encontramos, muitas vezes, uma autoestima elevada dos alunos que cursam o bacharelado em Educação Física e um sentimento de desvalorização profissional por parte dos licenciados.

Outro fator que reforça esse sentimento de desvalorização dos licenciados surge quando o professor mesmo sendo portador de todos os requisitos para desempenhar bem a sua profissão, ele não pode contar com os recursos necessários para desenvolver o seu trabalhado. Essa situação, tão comum nas escolas públicas, vai exigir do professor mais esforço, competência e criatividade, obviamente sem a devida retribuição salarial, também precarizada (KUENZER, 1999).

Todos esses empecilhos fazem com que os futuros professores de Educação Física almejem um novo mercado de trabalho (bacharelado, projetos sociais, pós-graduação, etc.) mesmo antes de terminarem o curso de licenciatura. $\mathrm{E}$ atrelado a estes novos rumos profissionais encontramos a expectativa de conseguir um bom salário e ter o reconhecimento social.

\section{Considerações finais}

Realizar modificações no campo da formação inicial em Educação Física não é uma tarefa fácil, pois exige que os professores formadores alterem as suas concepções, compreendam novas técnicas de ensino e contemplem as novas exigências políticas e curriculares.

O curso de formação inicial tem como principal objetivo desenvolver os conhecimentos e competências básicas para o exercício da profissão docente. Por isso, acreditamos que refletir sobre a formação inicial do professor é o caminho necessário para compreender melhor de que forma, por que e para quem está se dando a formação profissional.

Acreditamos que a formação do professor não pode limitar-se a um curso de licenciatura, pois esse não é capaz de suprir todas as necessidades impostas pelo cotidiano escolar. Por isso, é importante a formação continuada do professor. Entretanto, se o curso de formação inicial tiver uma base sólida em relação aos conhecimentos básicos da profissão, poderá ser capaz de legitimar a área de Educação Física no âmbito escolar.

Os cursos de formação inicial devem fornecer, além dos conteúdos das disciplinas que compõem a grade curricular, espaços propícios para a troca de conhecimentos, vivências práticas, reflexões teóricas e práticas, autorreflexões, desenvolvimento da autonomia, etc., contribuindo para que o professor possa enfrentar com desenvoltura as situações novas e diferentes que surgem no universo escolar. 
Apesar do avanço nas discussões sobre os temas abordados nessa pesquisa, acreditamos que os mesmos ainda carecem de maior esclarecimento e profundidade, por isso sugerimos que sejam realizadas outras pesquisas nessa área devido a sua relevância para a Educação Física e para a sociedade.

\section{Referências}

BASSO, I. S. Significado e sentido do trabalho docente. Caderno Cedes, ano XIX, n. 44, abril, p. 19-32, 1998.

BRASIL. Conselho Nacional de Educação/Câmara de Educação Superior. Resolução n. 07, de 31 de março de 2004.

BRASIL. Conselho Nacional de Educação. Resolução CNE/CP1, de 18 de fevereiro de 2002.

BRASIL. Lei de Diretrizes e Bases da Educação Nacional, de 20 de dezembro de 1996.

CESÁRIO, M. Formação de Professores de Educação Física da Universidade Estadual de Londrina: tradução do projeto curricular pelos professores. 2008. 221f. Tese (Doutorado em Educação) - Universidade Federal de São Carlos, São Carlos, 2008.

CRUZ, A. S. O embate de projetos na formação de professores de Educação Física: além da dualidade licenciatura - bacharelado. Motrivivência, ano XXIII, n. 36, p. 26-44, junho, 2011.

FONSECA, V. Da Filogênese à ontogênese da motricidade. Porto Alegre: Artes Médicas, 1988.

GIESTA, N. C. Cotidiano escolar e formação reflexiva do professor: moda ou valorização do saber docente? Araraquara: JM Editora, 2001.

IMPOLCETTO, F. M.; DARIDO, S. C. Ética como tema transversal: possibilidades de aplicação nas aulas de Educação Física Escolar. Motriz, Rio Claro, v.13, n.1, p. 14-23, jan/mar, 2007.

KUENZER, A. Z. As políticas de formação: A constituição da identidade do professor sobrante. Educação \& Sociedade. Campinas, ano XX, n. 68, p. 163-183, dez., 1999.

KRÜGER, L. G. As Concepções da Formação Profissional da Licenciatura em Educação Física: trajetórias docentes e suas perspectivas contributivas. 2007.137f. Dissertação (Mestrado em Educação) - Universidade Federal de Santa Maria, Santa Maria, 2007.

LIBÂNEO, J. C. Educação: pedagogia e didática - o campo investigativo da pedagogia e da didática no Brasil: esboço histórico e buscas de identidade epistemológica e profissional. In: PIMENTA, S. G. (Org.). Didática e formação de professores: percursos e perspectivas no Brasil e em Portugal. 4. ed. São Paulo: Cortez, 2006. p. 77-129.

MARCON, D.; GRAÇA, A. B. S.; NASCIMENTO, J. V. Critérios para a implementação de práticas pedagógicas na formação inicial em educação física e implicações no conhecimento pedagógico do conteúdo dos futuros professores. Revista Brasileira de Educação Física e Esporte, São Paulo, v.25, n.3, p.497-511, jul./set, 2011.

MARTINS, L. M. A formação social da personalidade do professor: um enfoque vigotskiano. Campinas, SP: Autores Associados, 2011.

MARX, K. Manuscritos econômico-filosóficos. Lisboa: Edições 70, 1989.

MENEZES, A. P.; et al. A ética na formação de professores: o olhar do licenciando da UFRJ. Revista Teias, v. 12, n. 25, p. 67-84, maio/ago, 2011.

SOARES, C. L.; et al. Metodologia do ensino de Educação Física/coletivo de autores. São Paulo: Cortez, 1992.

VÁZQUEZ, A. S. Filosofia da Praxis. Tradução de Luiz Fernando Cardoso. 2a ed. Rio de Janeiro: Editora Paz e Terra, 1977. 
Andreia Cristina Metzner

* Professora do Centro Universitário Unifafibe, São Paulo, Brasil.

\section{Correspondência}

Andreia Cristina Metzner - Centro Universitário Unifafibe. Rua Prof. Orlando França de Carvalho, 325, Centro, CEP: 14701-070 - São Paulo, São Paulo - Brasil.

E-mail: acmetzner@hotmail.com

Recebido em 04 de maio de 2015

Aprovado em 29 de agosto de 2016 